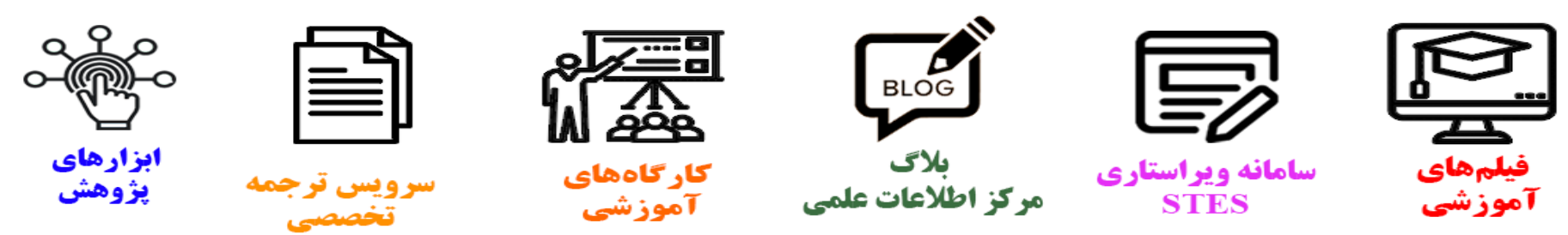

\title{
(c)
}

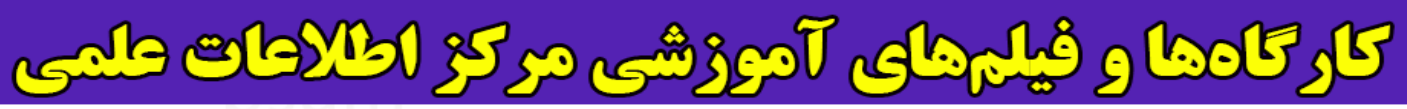
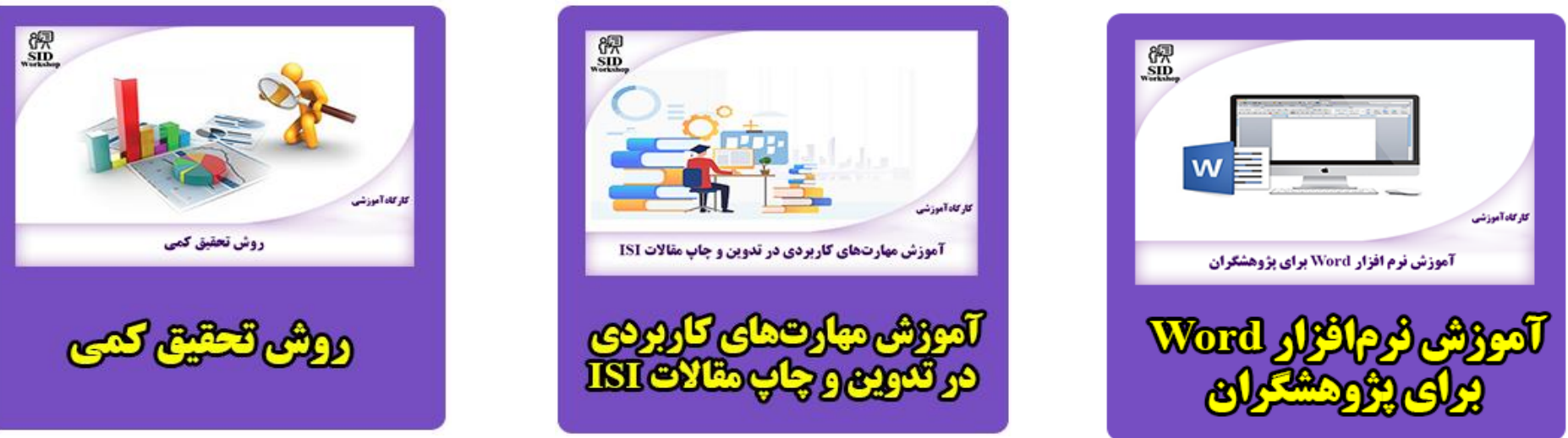


\title{
International Journal of Engineering
}

Journal Hom e page: ww w. ije.ir

\section{Energy Conservation Potential of the Heat Pipe Heat Exchangers: Experimental Study and Predictions}

\author{
M. Ahmadzadehtalatapeh ${ }^{a}, *, Y$. H. Yau b \\ a Department of Marine Engineering, Chabahar Maritime University, 99717-56499, Chabahar, Iran \\ ${ }^{b}$ Department of Mechanical Engineering, University of Malaya, 50603 Kuala Lumpur, Malaysia
}

\section{PAPER INFO}

Paper history:

Received 7 Aprill 2012

Received in revised form 25 Aprill 2012

Accepted 26 May 2012

\section{Keywords:}

Air Conditioning System

Energy Recovery

Heat Pipe Heat Exchanger

\section{$A B S T T R A C T$}

The energy conservation potential of the heat pipe based heat exchangers (HPHXs) was studied in this research. To this end, a typical climate chamber as the representative of an air conditioning system was established. The performance characteristic of a typical eight-row HPHX was obtained based on the one week operation $(168 \mathrm{~h})$ to determine the performance characteristic curves. The coil face velocity and inside temperature were set at $2 \mathrm{~m} / \mathrm{s}$ and $24{ }^{\circ} \mathrm{C}$, respectively. Then, the relevant empirical performance equations were used to predict the energy conservation of the HPHX for the years of 2000, 2020 , and 2050. The predictions showed that total amounts of $6,794 \mathrm{kWh}, 11,278 \mathrm{kWh}$, and 14,132 kWh energy could be recovered by the fabricated HPHX in the years of 2000, 2020, and 2050, respectively.

\section{INTRODUCTION}

Energy consumption of the most of the countries has been considerably increased especially in the developed countries. The increase of energy consumption has been realized due to the major developments in sectors such as industrial, transport, residential, and commercial sectors [1]. Moreover, based on the World Energy Council (WEC), with considering the current situation, the world energy demand would increase up to $50-80 \%$ in 2020. It can be anticipated that the energy consumption even has a faster growth in hot and tropical counties in comparison with the other counties. This is due to the fact that in these countries, the living standards have been improved and the application of energy consumers such as air conditioning (AC) systems has been considerably increased.

Besides the energy aspect, the global warming is a major issue now and it is one of the major challenges for the scientists and policy makers. The global warming negative effects on the world have already been obvious and UN nations gather annually for tackling this problem. There are some protocols such as

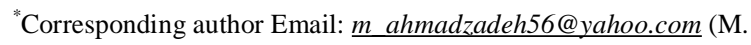
Ahmadzadehtalatapeh )
Kyoto Protocol that the UN nations have agreed on. Based on this protocol, the countries have agreed to impose policies to decrease the carbon emissions. One of the major methods which contribute to the emissions reduction is the application of energy recovery devices to improve the systems performance in terms of energy consumption.

In the building industry, the AC systems are one of the major energy consumers, and usually the operating power cost of the AC systems accounts for more than $50 \%$ of the entire energy bill [2]. How to reduce the energy consumption of the AC systems by using new energy recovery technologies and equipment is an important task for the designers and engineers.

Heat pipe heat exchanger (HPHX) as an efficient heat exchanger is suggested for this purpose. HPHXs can be used to recover energy between the fresh and return air. A HPHX is a heat exchanger consisting of externally-finned tubes filled with a proper refrigerant. There are two heat transfer sections in HPHX as the evaporator and condenser sections. In hot climates, the HPHXs can be used to cool incoming warm air and consequently decrease the energy demand in the $\mathrm{AC}$ systems. HPHX dose not need external power and because of design simplicity, it is a proper heat transfer device for energy recovering purpose [3, 4]. Application 
of the heat pipe based heat exchangers for heat transfer and energy recovering purposes has already been reported such as studies in [5- 12]. For instance, Azad [5] tested the performance of a heat pipe equipped solar collector. It was found that by applying this design, the production cost could be reduced by using an interconnected heat pipe because the heat pipes could be evacuated, sealed and tested at once.

Application of HPHXs for energy recovery in AC systems has been explored by some researches. The dehumidification capability of HPHX was studied by Abtahi et al. [6]. It was found that pre-cooling the air lowered the sensible cooling fraction and dehumidification capacity of the system was enhanced. In a similar research, a HPHX was examined for energy saving and dehumidification enhancement in an AC system in the subtropical Florida climate condition [7].

The HPHX was installed between the air streams in the system. The study showed an improvement in the dehumidification capability from 22 to $42 \%$ for the inlet temperature of $27^{\circ} \mathrm{C}$ and the relative humidity (RH) of $50 \%$. In addition, the results showed the average energy saving of $75 \%$ over the 1985 to 1986 . In another study, Mathur [8] used the BIN weather data (BIN weather data is the average of the real weather data that has been recorded over extended periods) to study the effect of a six-row HPHX in the energy consumption of an AC system. Yau [9] studied the effect of three key parameters of inlet air state namely, dry bulb temperature (DBT), RH and air velocity on the sensible heat ratio (SHR) of the 8-row thermosyphon HPHX. The study revealed that, by employing the HPHX, the overall SHR of the AC system was reduced from the maximum of 0.688 to the minimum of 0.188 as the evaporator inlet DBT was increased. Moreover, it was found that SHR was reduced from the maximum of 0.856 to the minimum of 0.188 as the evaporator inlet RH was increased. In another study, the influence of HPHXs on the enthalpy change in a tropical AC system was studied by Yau [10]. The tests and simulations conducted with/without an eight-row HPHX in an AC system. It was found that the added HPHX could improve the cooling load of the chilled water coil. Wan et al. [11] also tested the effect of a loop heat pipe air handling coil on the energy consumption in an $\mathrm{AC}$ system operating in an office building. According to the results, the AC system equipped with the HPHX could save cooling and reheating energy.

It was demonstrated that, for the indoor temperature of $22-26^{\circ} \mathrm{C}$ and $50 \% \mathrm{RH}$, the rate of energy saving in the office building was $23.5-25.7 \%$ for cooling load and $38.1-40.9 \%$ for total energy consumption. The study showed that by using a HPHX in an AC system, the energy consumption could be significantly reduced and the indoor thermal comfort could also be improved. A 3-row thermosyphon HPHX was studied using the Hilton AC laboratory Unit in RMIT [12]. The capability of added HPHX for energy recovering and RH control of supplied air was investigated in the study. Based on the experimental results, the cooling capability for the system was improved by 20 to $32.7 \%$. It was also found that for $\mathrm{RH}$ situations below $70 \% \mathrm{RH}$, the condenser side of the HPHX could also perform as a reheater to replace with the reheating coil to control the $\mathrm{RH}$ parameter. As a result of this study, the application of HPHXs instead of conventional reheat coils was suggested.

Almost in all of the previous research studies, performance of the HPHX has been considered as a fixed parameter. However, the empirical performance equation of the heat exchanger under actual conditions can lead to more reliable and acceptable findings and predictions. In this research, the capability of a typical eight-row HPHX for energy recovering was investigated in the AC systems operating in hot and tropical areas. To this end, the performance characteristic of the fabricated eight-row HPHX was obtained during one week of operation. This is performed to find out more reliable data for the simulations and predictions. The experiments were conducted in Kuala Lumpur, Malaysia as a hot and tropical region.

\section{METHODOLOGY}

The present research can be divided into two main parts. First part is the experimental work and the second part is the predictions or the simulations. In the experimental part, the fabricated HPHX was installed in an established experimental AC system, and the performance curves of the HPHX were obtained based on the one week (168 h) operation. Then, in the simulation part the empirical performance equations of the HPHX were extracted from the performance curves and were used in a simulation program to predict the energy recovery potential of the fabricated HPHX for the upcoming year.

The test set-up consists of a removable HPHX, a fan coil unit, an electric heater and a variable speed fan. The HPHX, measurement sections, and ducts were fully insulated to minimize heat transfer to the atmosphere. The HPHX operated in the horizontal configuration, as illustrated in Figure 1. In the operation process, HPHX pre-cooled the fresh air in the evaporator side before reaching into the cooling coil. The physical specifications of the fabricated eight-row HPHX are listed in Table 1.

The fan coil unit consisted of two units of $(9390 \mathrm{~W}$ total cooling capability) cooling coils and a centrifugal fan to blow the air to the space. In addition, a $5.5 \mathrm{~kW}$ electric heater with a control box was installed after the 
fan coil unit to provide the desired inside air temperature. A variable speed fan was also located inside the ducting system to establish the required coil face velocity or mass flow rate.

TABLE 1. Design specifications of the HPHX

\begin{tabular}{ll}
\hline HPHX dimensions & 420 mm wide, $350 \mathrm{~mm}$ high \\
Number of rows & $\begin{array}{l}\text { Eight rows of } 11 \text { tubes, OD:13.4 mm, } \\
\text { ID:12.7 mm }\end{array}$ \\
$\begin{array}{l}\text { Centre-to-centre tube } \\
\text { spacing }\end{array}$ & $\begin{array}{l}\text { Transverse: } 31.75 \mathrm{~mm} \text {,Longitudinal: } 27.5 \\
\mathrm{~mm}\end{array}$ \\
Fin & $\begin{array}{l}\text { Aluminum corrugated, wavy plate, } 12 \mathrm{fin} \\
\text { per inch, fin thickness: } 0.15 \mathrm{~mm}\end{array}$ \\
& $\begin{array}{l}\text { Three layers of stainless steel wire mesh, } \\
\text { Wick structure }\end{array}$ \\
Refrigerant & R-134a (HFC family)
\end{tabular}

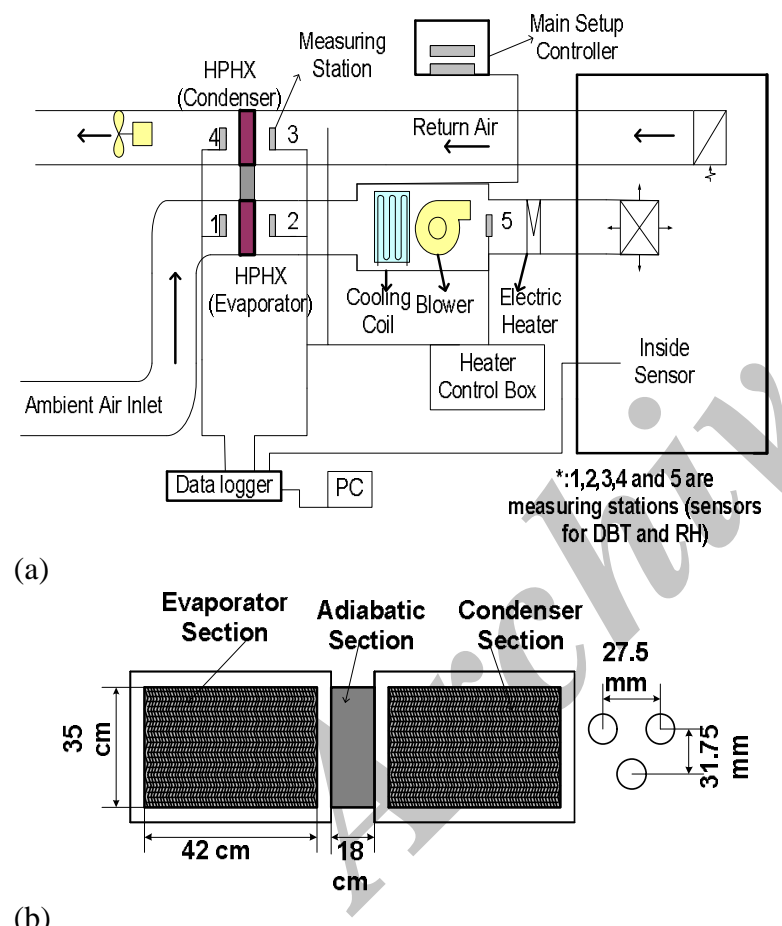

Figure 1. (a) Schematic diagram of the test set-up, and (b) Schematic of the HPHX and tube arrangements

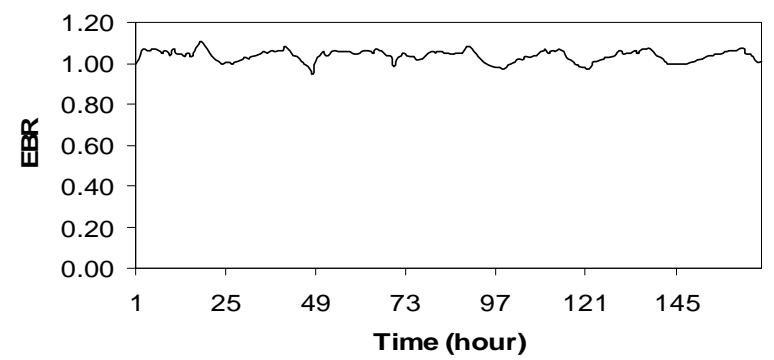

Figure 2. Hourly recorded EBR value
The RH and DBT of the air at each measuring point were recorded using the $\mathrm{RH}$ and resistance temperature detector (RTD) sensors. Before the instrumentation of the test set-up, all the sensors were calibrated in the range of expected operation and the recorded data were analyzed by a data acquisition software.

The parameters which concerned in this study were: coil face velocity and inside temperature. The HPHX was directly receiving the fresh outdoor air in the evaporator side. The coil face velocity was provided at 2 $\mathrm{m} / \mathrm{s}$, which typically occurs in practice, and return air temperature was set at $24^{\circ} \mathrm{C}$ as the approximation for the inside air temperature.

In order to obtain the performance curves, DBT and $\mathrm{RH}$ of the air at each measuring point were recorded every minute, and average of the sixty measurements was used for the data processing purpose. The system was run for $168 \mathrm{~h}$ (one week) and the performance curves of the HPHX were obtained.

\section{RESULTS AND DISCUSSIONS}

Before the data processing, in order to check the reliability of the recorded data, the energy balance ratio (EBR) in the HPHX was recorded (see Figure 2). EBR value shows the heat transfer ratio between the evaporator and condenser sides. It was observed that the EBR value fluctuated between 0.95 and 1.1 with the mean value of 1.1 .

As illustrated in Figure 2, the EBR value deviates from unity. This deviation is expected, since the heat transfer process of the system is a transient heat transfer. Moreover, non-uniformity of the temperature profile at the measuring stations is also expected. The nonuniformity of the temperature causes uncertainty in the recorded data, which is estimated in section 3.1.

Figure 3 shows the hourly recorded ambient temperature and $\mathrm{RH}$ during the data collection. The $\mathrm{RH}$ was ranging between $45 \%$ and $89 \%$ and ambient temperature was in the range of $24^{\circ} \mathrm{C}$ to $34^{\circ} \mathrm{C}$. The recorded temperature and $\mathrm{RH}$ of the measuring points were shown in Figure 4. According to the Figure 4, the evaporator inlet temperature and $\mathrm{RH}$ fluctuation are much more than other measuring points and this is because of the fact that there is no control in outdoor air conditions and the system receives exactly the fresh outdoor air. The RH and temperature changes after the HPHX sections are also illustrated in Figure 4.

As mentioned earlier in the paper, the main goal of the present experimental research work is to understand the energy conservation or energy recovery potential of the fabricated eight-row HPHX. Almost in all of the previous research works, the effectiveness of the HPHXs was considered as a fixed parameter (Note: 
effectiveness is defines as the actual heat transfer rate to the maximum possible heat transfer rate.).

However, the performance of the HPHX in actual conditions may not be fixed. As a result, determining the relevant empirical equations based on one week operation in actual condition make the energy analysis of the HPHX more accurate and reliable. The recorded effectiveness of the HPHX was fluctuated between $42 \%$ and $51 \%$, as shown in Figure 5.

The empirical relationships between the evaporator inlet and outlet temperatures (EIT and EOT) were extracted from the performance characteristic curves. Therefore, the evaporator inlet air $\mathrm{RH}$ was categorized into five ranges, namely $40 \%-50 \%, 50 \%-60 \%, 60 \%$ $70 \%, 70 \%-80 \%$, and $80 \%-100 \%$ and the empirical performance equations for the evaporator section were obtained (with the highest goodness of fit value, $R^{2}$ ) and tabulated in Table 2. Figure 6 illustrates the typical performance curve for the RH category of $60 \%-70 \%$ as a representative.

For accurate and reliable predictions of the energy recovery by the HPHX for the whole years at 2000, 2020, and 2050, the yearly temperature and RH data together with the empirical performance equations of the HPHX were considered. To this end, the predicted TMY weather data for the years 2000, 2020, and 2050 was used [13].

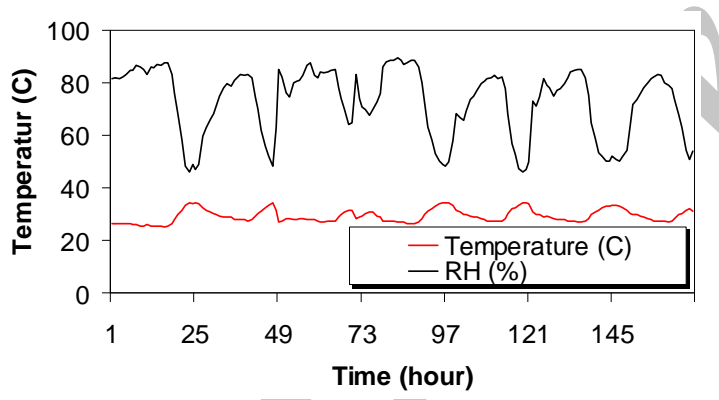

Figure 3. The recorded ambient temperature and $\mathrm{RH}$ during the test

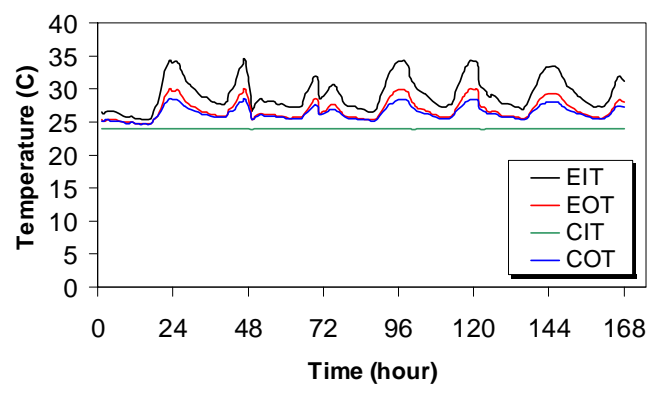

Figure 4. The recorded temperature and $\mathrm{RH}$ of the measuring points

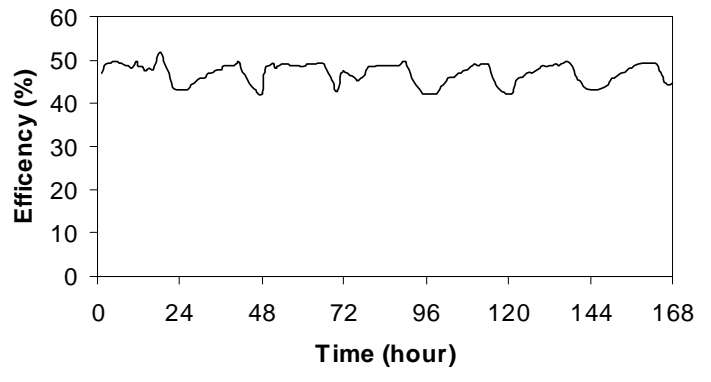

Figure 5. Recorded efficiency during the test

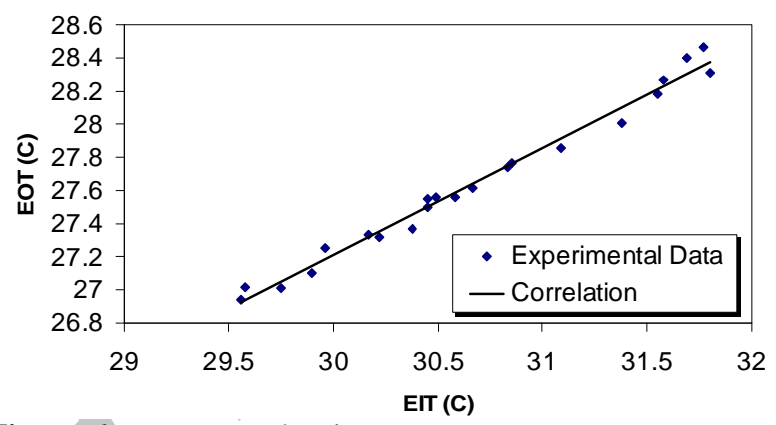

Figure 6. Evaporator leaving temperature versus evaporator inlet temperature for typical $60 \% \leq \mathrm{RH}<70 \%$

TABLE 2. Empirical equations

\begin{tabular}{l|ll}
\hline 1 & $0 \%<R H \leq 50 \%$ & $E O T=0.6628 * E I T+7.195$ \\
2 & $50 \%<R H \leq 60 \%$ & $E O T=0.645 * E I T+7.822$ \\
3 & $60 \%<R H \leq 70 \%$ & $E O T=0.6476 * E I T+7.7807$ \\
4 & $70 \%<R H \leq 80 \%$ & $E O T=0.5866 * E I T+9.6301$ \\
5 & $80 \%<R H \leq 100 \%$ & $E O T=0.5017 * E I T+12.005$ \\
\hline
\end{tabular}

The predicted TMY weather files were generated by adapting the current industry standard weather files to incorporate climate change predictions [13]. The data files provide the hourly weather data for the whole year of 8760 hours for the tropical Kuala Lumpur climate.

The hour-by-hour weather data together with the relevant empirical equations were used for the calculations of the energy recovery by the HPHX. Therefore, the empirical equations of the HPHX, which were extracted from the performance curves, were written as a FORTRAN source code to represent the HPHX in TRNSYS software (TRNSYS software is a transient systems simulation software with a modular structure).

TRNSYS software was used to read the hour-byhour data from the TMY weather files and compute the data for the whole years. Then, the energy recovery by the HPHX evaporator section was simulated hour-byhour for the whole year of $8760 \mathrm{~h}$. This prediction was 
performed for the years of 2000, 2020, and 2050, as illustrated in Figures 7-9.

Based on the simulation results, it was found that the energy recovery by the evaporator section of the HPHX was estimated at $3397 \mathrm{kWh}, 5639 \mathrm{kWh}$, and $7066 \mathrm{kWh}$ for 2000, 2020, and 2050, respectively. Moreover, if the energy rejected in the condenser section could be used for heating process, the amount of energy recovery by the HPHX could be increased up to $6794 \mathrm{kWh}$, $11278 \mathrm{kWh}$, and $14132 \mathrm{kWh}$ for the years 2000, 2020, and 2050, respectively. Table 3 shows the capability of the HPHX for energy recovering. As tabulated in Table 3 , the energy recovery potential of the HPHX increases from 2000 to 2050. In percentage terms, the predictions showed that the energy recovery potential of the fabricated HPHX could increase up to $66 \%$ and $108 \%$ in years 2020 and 2050 in comparison to year 2000, respectively. This is attributed to the fact that, the inlet temperature to the evaporator section would be higher in coming years; therefore, the temperature drop in the evaporator section expected to be increased.

It is clear that the amount of energy recovery by a heat exchanger depends on the amount of the ventilated air in the system. As already explained, the above described climate chamber is a small scale of the AC systems.

In the climate chamber under test, the system received 622 CFM (cubic feet per minute) of air, which was almost suitable for a small room of about $20 \mathrm{~m}^{3}$, and the energy recovered by the HPHX was based on the above ventilated air; therefore, it could be anticipated that the amount of energy recovery in the actual AC systems would be much higher than the above mentioned amounts. For example, in the study reported in [11] the energy saving of the system with the added loop heat pipe was estimated to be about 140 $\mathrm{kW} / \mathrm{h}$, which is considerable in an actual AC system.

Therefore, by considering all the above, HPHXs as an environmentally friendly technology could be an appropriate heat recovery device for coming years. Moreover, based on the interesting energy recovery capability of the HPHXs in AC systems, AC systems are recommended to be equipped with this heat recovery device to improve the system performance in terms of energy consumption.

\subsection{Uncertainty analysis Bias uncertainty} ( $B_{\text {Tdependent }}$ ) because of the non-uniformity in the temperature profile was estimated for the recorded parameters in this research. The bias uncertainty for the dependent variables that results from a non-uniform temperature distribution at a measuring point can be approximately represented by:

$$
B_{\text {Tdependent }}=\frac{X_{\max }-X_{\min }}{n}
$$

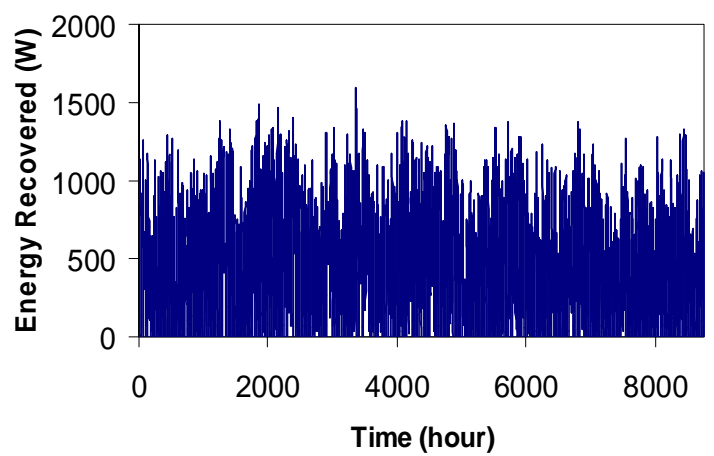

Figure 7. Energy recovered by the evaporator section of the HPHX, simulation for the whole year- year 2000

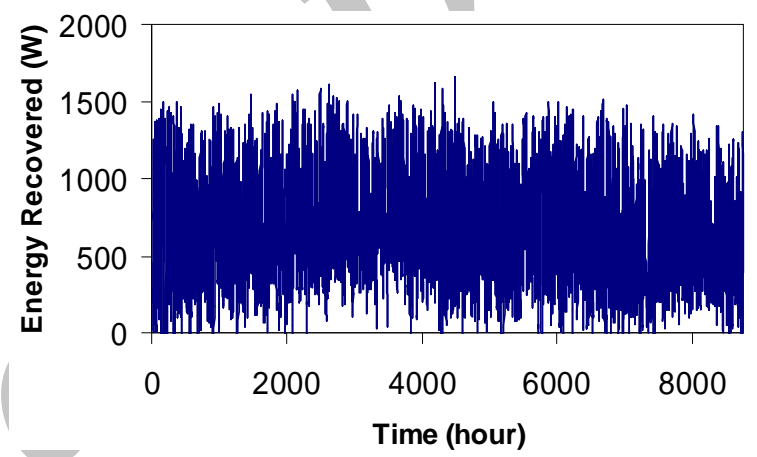

Figure 8. Energy recovered by the evaporator section of the HPHX, simulation for the whole year- year 2020

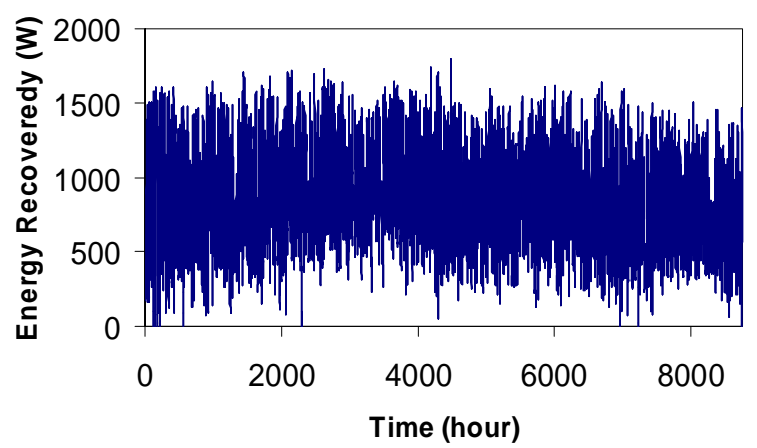

Figure 9. Energy recovered by the evaporator section of the HPHX, simulation for the whole year- year 2050

TABLE 3. Energy recovery by the HPHX

\begin{tabular}{llll}
\hline Year & $\begin{array}{l}\text { By the } \\
\text { evaporator } \\
\text { section of the } \\
\text { HPHX }(\mathbf{k W h})\end{array}$ & $\begin{array}{l}\text { By the } \\
\text { evaporator } \\
\text { and condenser } \\
\text { sections of the } \\
\text { HPHX }(\mathbf{k W h})\end{array}$ & $\begin{array}{l}\text { Improvement } \\
(\boldsymbol{\%})\end{array}$ \\
\hline 2000 & 3397 & 6794 & - \\
2020 & 5639 & 11278 & 66 \\
2050 & 7066 & 14132 & 108 \\
\hline
\end{tabular}


where $X$ is the dependent variable (effectiveness and EBR in this research), $n$ is the number of dependent variables, $X_{\max }$ and $X_{\min }$ are the maximum and minimum dependent variables calculated based on the maximum and minimum temperatures at the measuring points.

In this study, the bias uncertainty for the hourly recorded effectiveness and EBR was calculated. To this end, maximum amount of parameter $\left(X_{\max }\right)$ is calculated based on the maximum recorded temperature at the measuring points and minimum amount of parameter $\left(X_{\text {min }}\right)$ is calculated based on the minimum recorded temperature at the measuring points. Figure 10 shows the hourly calculated bias uncertainty for the effectiveness and EBR parameters. It was found that the uncertainty for the EBR values was ranging from $0 \%$ to $6.8 \%$ and for effectiveness parameter was varied from of $0 \%$ to $4.9 \%$.

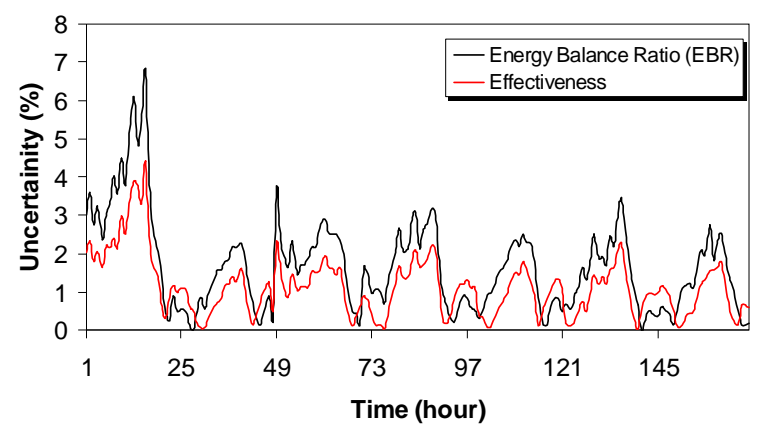

Figure 10. Hourly calculated bias uncertainty for the EBR and effectiveness

\section{CONCLUSION}

In this research, the capability of HPHXs for energy recovering was estimated for the whole year of $8760 \mathrm{~h}$ at 2000, 2020, and 2050. For this purpose, the empirical performance equations of the HPHX were used in TRNSYS software. Based on the simulation results, the fabricated eight-row HPHX has the capability of energy recovery at $6794 \mathrm{kWh}, 11278 \mathrm{kWh}$, and $14132 \mathrm{kWh}$ for the years 2000, 2020, and 2050, respectively. Moreover, the predictions showed that the energy recovery potential of the fabricated HPHX could increase up to $66 \%$ and $108 \%$ in years 2020 and 2050 in comparison to year 2000, respectively. Therefore, it is anticipated that HPHXs can recover a considerable amount of energy in a yearly operation if they could be installed in the actual $\mathrm{AC}$ systems and they are recommended to be used in the $\mathrm{AC}$ systems to improve the systems performance in terms of energy consumption.

\section{ACKNOWLEDGMENTS}

The author would like to acknowledge the financial assistance from the Chabahar Maritime University, Iran and University of Malaya, Malaysia for the research work.

\section{REFERENCES}

1. Hunt, V.D., Handbook of conservation and solar energy, trends and perspectives. Van Nostrand Reinhold Company, (1982).

2. Yau, Y.H., "The use of a double heat pipe heat exchanger system for reducing energy consumption of treating ventilation air in an operating theatre - A full year energy consumption model simulation", Energy and Buildings, Vol. 40, (2008), 917925 .

3. Abd El-Baky, M.A. and Mohamed, M.M., "Heat pipe heat exchanger for heat recovery in air conditioning", Applied Thermal Engineering, Vol. 27, (2007), 795-801.

4. Shirey III, D.B., "Demonstration of efficient humidity control techniques at an art museum", ASHRAE Transactions, Vol. 99, No. 1, (1993), 694-703.

5. Azad, E., "Interconnected heat pipe solar collect", International Journal of Engineering Transactions A: Basics, Vol. 22, No. 3, (2009), 233-242.

6. Abtahi, H., Jayanth, M. and Khattar, M.K., "Theoretical Analysis of the Performance Characteristics of Dehumidification Heat Pipe Heat Exchangers in Air-Conditioning Systems", In ASME Proceedings of the 1988 National Heat Transfer Conference, Houston, TX, USA, Vol. 2, (1998), 1391-1396.

7. Khattar, M.K., "Heat pipes for terrestrial applications in dehumidification systems", Space Congress, $25^{\text {th }}$, Proceedings (A88-52317 23-12), FL, USA, 26-29, (1988).

8. Mathur, G.D., "Predicting yearly energy savings using BIN weather data with heat pipe heat exchangers", In Proceeding of the Intersociety Energy Conversion Engineering Conference, Honolulu, USA, Vol. 2, (1997), 1391-1396.

9. Yau, Y.H., "Application of a heat pipe heat exchanger to dehumidification enhancement in a HVAC system for tropical climates- a base line performance characteristic study", International Journal of Thermal Science, Vol. 46, (2007), 164-171.

10. Yau, Y.H., "Analysis of enthalpy change with/without a heat pipe heat exchanger in a tropical air conditioning system", International Journal of Energy Research, Vol. 30, No. 15, (2006), 1251-1263.

11. Wan, J.W., Zhang, J.L. and Zhang, W.M., "The effect of heat pipe air handling coil on energy consumption in central air conditioning system", Energy and Buildings, Vol. 39, (2007), 1035-1040.

12. Wu, X.P., Johnson, P. and Akbarzadeh, A., "Application of heat pipe heat exchangers to humidity control in air-conditioning systems", Applied Thermal Engineering, Vol. 17, No. 6, (1997), 561-568.

13. Jentsch, M.F., Chang, C.K., James, P.A.B., Bahaj, A.S. and Yau, Y.H., "Development of Climate Change Adapted Weather Files for Building Performance Simulation: Implications for Southeast Asia”, World Renewable Energy Congress 2009 - Asia, The 3rd International Conference on Sustainable Energy and Environment (SEE 2009), Bangkok, Thailand, (2009). 


\section{Energy Conservation Potential of the Heat Pipe Heat Exchangers: Experimental Study and Predictions}

M. Ahmadzadehtalatapeh ${ }^{a}$,Y. H. Yau ${ }^{\mathrm{b}}$

a Department of Marine Engineering, Chabahar Maritime University, 99717-56499, Chabahar, Iran

${ }^{b}$ Department of Mechanical Engineering, University of Malaya, 50603 Kuala Lumpur, Malaysia

\section{$P A P E R \quad I N F O$}

جكيده

Paper history:

Received 7 Aprill 2012

Received in revised form 25 Aprill 2012

Accepted 26 May 2012

\section{Keywords:}

Air Conditioning System

Energy Recovery

Heat Pipe Heat Exchanger

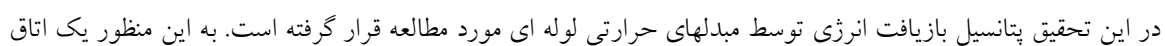

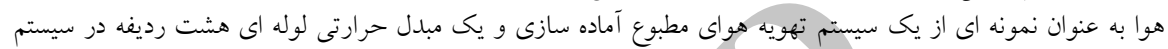

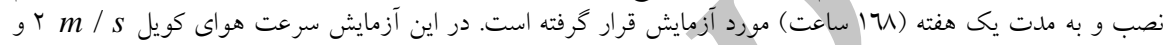

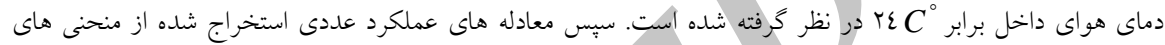

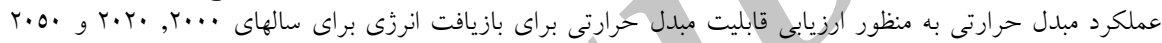

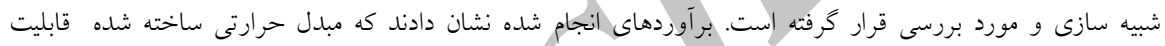

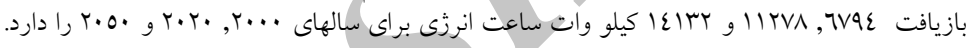

doi: 10.5829/idosi.ije.2012.25.03b.06 


\title{
International Journal of Engineering
}

Journal Hom e page: ww w. ije.ir

\section{Energy Conservation Potential of the Heat Pipe Heat Exchangers: Experimental Study and Predictions}

\author{
M. Ahmadzadehtalatapeh ${ }^{a}, *, Y$. H. Yau b \\ a Department of Marine Engineering, Chabahar Maritime University, 99717-56499, Chabahar, Iran \\ ${ }^{b}$ Department of Mechanical Engineering, University of Malaya, 50603 Kuala Lumpur, Malaysia
}

\section{PAPER INFO}

Paper history:

Received 7 Aprill 2012

Received in revised form 25 Aprill 2012

Accepted 26 May 2012

\section{Keywords:}

Air Conditioning System

Energy Recovery

Heat Pipe Heat Exchanger

\section{$A B S T T R A C T$}

The energy conservation potential of the heat pipe based heat exchangers (HPHXs) was studied in this research. To this end, a typical climate chamber as the representative of an air conditioning system was established. The performance characteristic of a typical eight-row HPHX was obtained based on the one week operation $(168 \mathrm{~h})$ to determine the performance characteristic curves. The coil face velocity and inside temperature were set at $2 \mathrm{~m} / \mathrm{s}$ and $24{ }^{\circ} \mathrm{C}$, respectively. Then, the relevant empirical performance equations were used to predict the energy conservation of the HPHX for the years of 2000, 2020 , and 2050. The predictions showed that total amounts of $6,794 \mathrm{kWh}, 11,278 \mathrm{kWh}$, and 14,132 kWh energy could be recovered by the fabricated HPHX in the years of 2000, 2020, and 2050, respectively.

\section{INTRODUCTION}

Energy consumption of the most of the countries has been considerably increased especially in the developed countries. The increase of energy consumption has been realized due to the major developments in sectors such as industrial, transport, residential, and commercial sectors [1]. Moreover, based on the World Energy Council (WEC), with considering the current situation, the world energy demand would increase up to $50-80 \%$ in 2020. It can be anticipated that the energy consumption even has a faster growth in hot and tropical counties in comparison with the other counties. This is due to the fact that in these countries, the living standards have been improved and the application of energy consumers such as air conditioning (AC) systems has been considerably increased.

Besides the energy aspect, the global warming is a major issue now and it is one of the major challenges for the scientists and policy makers. The global warming negative effects on the world have already been obvious and UN nations gather annually for tackling this problem. There are some protocols such as

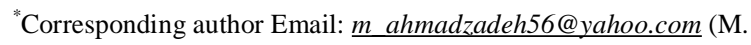
Ahmadzadehtalatapeh )
Kyoto Protocol that the UN nations have agreed on. Based on this protocol, the countries have agreed to impose policies to decrease the carbon emissions. One of the major methods which contribute to the emissions reduction is the application of energy recovery devices to improve the systems performance in terms of energy consumption.

In the building industry, the AC systems are one of the major energy consumers, and usually the operating power cost of the AC systems accounts for more than $50 \%$ of the entire energy bill [2]. How to reduce the energy consumption of the AC systems by using new energy recovery technologies and equipment is an important task for the designers and engineers.

Heat pipe heat exchanger (HPHX) as an efficient heat exchanger is suggested for this purpose. HPHXs can be used to recover energy between the fresh and return air. A HPHX is a heat exchanger consisting of externally-finned tubes filled with a proper refrigerant. There are two heat transfer sections in HPHX as the evaporator and condenser sections. In hot climates, the HPHXs can be used to cool incoming warm air and consequently decrease the energy demand in the $\mathrm{AC}$ systems. HPHX dose not need external power and because of design simplicity, it is a proper heat transfer device for energy recovering purpose [3, 4]. Application 
of the heat pipe based heat exchangers for heat transfer and energy recovering purposes has already been reported such as studies in [5- 12]. For instance, Azad [5] tested the performance of a heat pipe equipped solar collector. It was found that by applying this design, the production cost could be reduced by using an interconnected heat pipe because the heat pipes could be evacuated, sealed and tested at once.

Application of HPHXs for energy recovery in AC systems has been explored by some researches. The dehumidification capability of HPHX was studied by Abtahi et al. [6]. It was found that pre-cooling the air lowered the sensible cooling fraction and dehumidification capacity of the system was enhanced. In a similar research, a HPHX was examined for energy saving and dehumidification enhancement in an AC system in the subtropical Florida climate condition [7].

The HPHX was installed between the air streams in the system. The study showed an improvement in the dehumidification capability from 22 to $42 \%$ for the inlet temperature of $27^{\circ} \mathrm{C}$ and the relative humidity (RH) of $50 \%$. In addition, the results showed the average energy saving of $75 \%$ over the 1985 to 1986 . In another study, Mathur [8] used the BIN weather data (BIN weather data is the average of the real weather data that has been recorded over extended periods) to study the effect of a six-row HPHX in the energy consumption of an AC system. Yau [9] studied the effect of three key parameters of inlet air state namely, dry bulb temperature (DBT), RH and air velocity on the sensible heat ratio (SHR) of the 8-row thermosyphon HPHX. The study revealed that, by employing the HPHX, the overall SHR of the AC system was reduced from the maximum of 0.688 to the minimum of 0.188 as the evaporator inlet DBT was increased. Moreover, it was found that SHR was reduced from the maximum of 0.856 to the minimum of 0.188 as the evaporator inlet RH was increased. In another study, the influence of HPHXs on the enthalpy change in a tropical AC system was studied by Yau [10]. The tests and simulations conducted with/without an eight-row HPHX in an AC system. It was found that the added HPHX could improve the cooling load of the chilled water coil. Wan et al. [11] also tested the effect of a loop heat pipe air handling coil on the energy consumption in an $\mathrm{AC}$ system operating in an office building. According to the results, the AC system equipped with the HPHX could save cooling and reheating energy.

It was demonstrated that, for the indoor temperature of $22-26^{\circ} \mathrm{C}$ and $50 \% \mathrm{RH}$, the rate of energy saving in the office building was $23.5-25.7 \%$ for cooling load and $38.1-40.9 \%$ for total energy consumption. The study showed that by using a HPHX in an AC system, the energy consumption could be significantly reduced and the indoor thermal comfort could also be improved. A 3-row thermosyphon HPHX was studied using the Hilton AC laboratory Unit in RMIT [12]. The capability of added HPHX for energy recovering and RH control of supplied air was investigated in the study. Based on the experimental results, the cooling capability for the system was improved by 20 to $32.7 \%$. It was also found that for $\mathrm{RH}$ situations below $70 \% \mathrm{RH}$, the condenser side of the HPHX could also perform as a reheater to replace with the reheating coil to control the $\mathrm{RH}$ parameter. As a result of this study, the application of HPHXs instead of conventional reheat coils was suggested.

Almost in all of the previous research studies, performance of the HPHX has been considered as a fixed parameter. However, the empirical performance equation of the heat exchanger under actual conditions can lead to more reliable and acceptable findings and predictions. In this research, the capability of a typical eight-row HPHX for energy recovering was investigated in the AC systems operating in hot and tropical areas. To this end, the performance characteristic of the fabricated eight-row HPHX was obtained during one week of operation. This is performed to find out more reliable data for the simulations and predictions. The experiments were conducted in Kuala Lumpur, Malaysia as a hot and tropical region.

\section{METHODOLOGY}

The present research can be divided into two main parts. First part is the experimental work and the second part is the predictions or the simulations. In the experimental part, the fabricated HPHX was installed in an established experimental AC system, and the performance curves of the HPHX were obtained based on the one week (168 h) operation. Then, in the simulation part the empirical performance equations of the HPHX were extracted from the performance curves and were used in a simulation program to predict the energy recovery potential of the fabricated HPHX for the upcoming year.

The test set-up consists of a removable HPHX, a fan coil unit, an electric heater and a variable speed fan. The HPHX, measurement sections, and ducts were fully insulated to minimize heat transfer to the atmosphere. The HPHX operated in the horizontal configuration, as illustrated in Figure 1. In the operation process, HPHX pre-cooled the fresh air in the evaporator side before reaching into the cooling coil. The physical specifications of the fabricated eight-row HPHX are listed in Table 1.

The fan coil unit consisted of two units of $(9390 \mathrm{~W}$ total cooling capability) cooling coils and a centrifugal fan to blow the air to the space. In addition, a $5.5 \mathrm{~kW}$ electric heater with a control box was installed after the 
fan coil unit to provide the desired inside air temperature. A variable speed fan was also located inside the ducting system to establish the required coil face velocity or mass flow rate.

TABLE 1. Design specifications of the HPHX

\begin{tabular}{ll}
\hline HPHX dimensions & 420 mm wide, $350 \mathrm{~mm}$ high \\
Number of rows & $\begin{array}{l}\text { Eight rows of } 11 \text { tubes, OD:13.4 mm, } \\
\text { ID:12.7 mm }\end{array}$ \\
$\begin{array}{l}\text { Centre-to-centre tube } \\
\text { spacing }\end{array}$ & $\begin{array}{l}\text { Transverse: } 31.75 \mathrm{~mm} \text {,Longitudinal: } 27.5 \\
\mathrm{~mm}\end{array}$ \\
Fin & $\begin{array}{l}\text { Aluminum corrugated, wavy plate, } 12 \mathrm{fin} \\
\text { per inch, fin thickness: } 0.15 \mathrm{~mm}\end{array}$ \\
& $\begin{array}{l}\text { Three layers of stainless steel wire mesh, } \\
\text { Wick structure }\end{array}$ \\
Refrigerant & R-134a (HFC family)
\end{tabular}

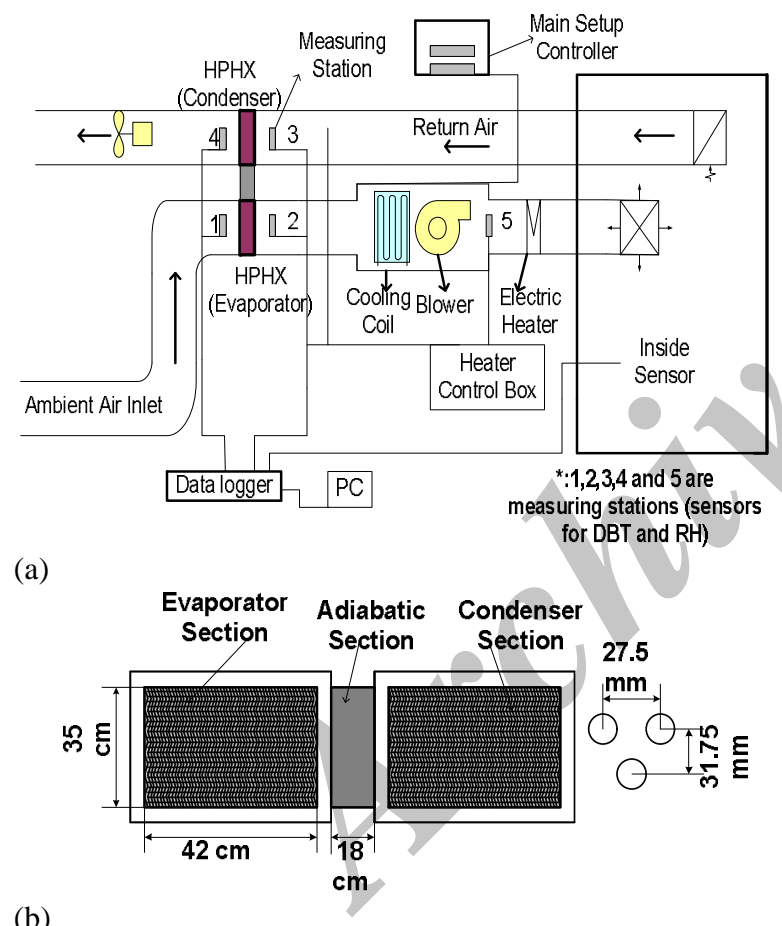

Figure 1. (a) Schematic diagram of the test set-up, and (b) Schematic of the HPHX and tube arrangements

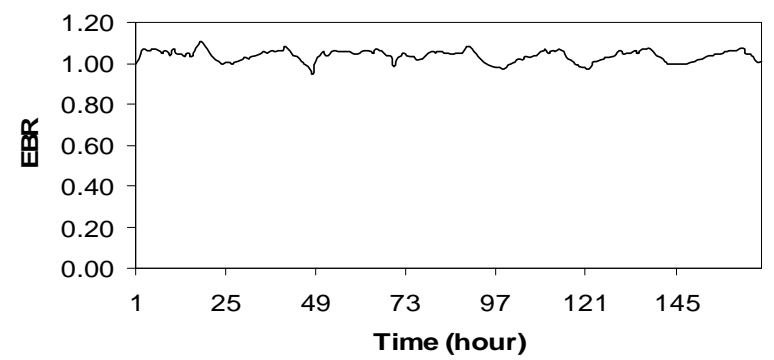

Figure 2. Hourly recorded EBR value
The RH and DBT of the air at each measuring point were recorded using the $\mathrm{RH}$ and resistance temperature detector (RTD) sensors. Before the instrumentation of the test set-up, all the sensors were calibrated in the range of expected operation and the recorded data were analyzed by a data acquisition software.

The parameters which concerned in this study were: coil face velocity and inside temperature. The HPHX was directly receiving the fresh outdoor air in the evaporator side. The coil face velocity was provided at 2 $\mathrm{m} / \mathrm{s}$, which typically occurs in practice, and return air temperature was set at $24^{\circ} \mathrm{C}$ as the approximation for the inside air temperature.

In order to obtain the performance curves, DBT and $\mathrm{RH}$ of the air at each measuring point were recorded every minute, and average of the sixty measurements was used for the data processing purpose. The system was run for $168 \mathrm{~h}$ (one week) and the performance curves of the HPHX were obtained.

\section{RESULTS AND DISCUSSIONS}

Before the data processing, in order to check the reliability of the recorded data, the energy balance ratio (EBR) in the HPHX was recorded (see Figure 2). EBR value shows the heat transfer ratio between the evaporator and condenser sides. It was observed that the EBR value fluctuated between 0.95 and 1.1 with the mean value of 1.1 .

As illustrated in Figure 2, the EBR value deviates from unity. This deviation is expected, since the heat transfer process of the system is a transient heat transfer. Moreover, non-uniformity of the temperature profile at the measuring stations is also expected. The nonuniformity of the temperature causes uncertainty in the recorded data, which is estimated in section 3.1.

Figure 3 shows the hourly recorded ambient temperature and $\mathrm{RH}$ during the data collection. The $\mathrm{RH}$ was ranging between $45 \%$ and $89 \%$ and ambient temperature was in the range of $24^{\circ} \mathrm{C}$ to $34^{\circ} \mathrm{C}$. The recorded temperature and $\mathrm{RH}$ of the measuring points were shown in Figure 4. According to the Figure 4, the evaporator inlet temperature and $\mathrm{RH}$ fluctuation are much more than other measuring points and this is because of the fact that there is no control in outdoor air conditions and the system receives exactly the fresh outdoor air. The RH and temperature changes after the HPHX sections are also illustrated in Figure 4.

As mentioned earlier in the paper, the main goal of the present experimental research work is to understand the energy conservation or energy recovery potential of the fabricated eight-row HPHX. Almost in all of the previous research works, the effectiveness of the HPHXs was considered as a fixed parameter (Note: 
effectiveness is defines as the actual heat transfer rate to the maximum possible heat transfer rate.).

However, the performance of the HPHX in actual conditions may not be fixed. As a result, determining the relevant empirical equations based on one week operation in actual condition make the energy analysis of the HPHX more accurate and reliable. The recorded effectiveness of the HPHX was fluctuated between $42 \%$ and $51 \%$, as shown in Figure 5.

The empirical relationships between the evaporator inlet and outlet temperatures (EIT and EOT) were extracted from the performance characteristic curves. Therefore, the evaporator inlet air $\mathrm{RH}$ was categorized into five ranges, namely $40 \%-50 \%, 50 \%-60 \%, 60 \%$ $70 \%, 70 \%-80 \%$, and $80 \%-100 \%$ and the empirical performance equations for the evaporator section were obtained (with the highest goodness of fit value, $R^{2}$ ) and tabulated in Table 2. Figure 6 illustrates the typical performance curve for the RH category of $60 \%-70 \%$ as a representative.

For accurate and reliable predictions of the energy recovery by the HPHX for the whole years at 2000, 2020, and 2050, the yearly temperature and RH data together with the empirical performance equations of the HPHX were considered. To this end, the predicted TMY weather data for the years 2000, 2020, and 2050 was used [13].

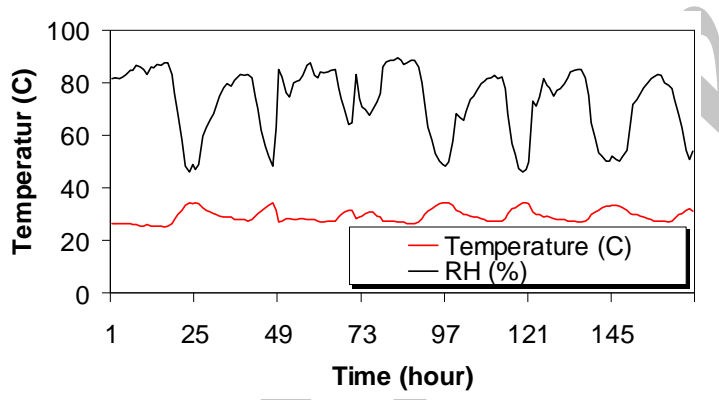

Figure 3. The recorded ambient temperature and $\mathrm{RH}$ during the test

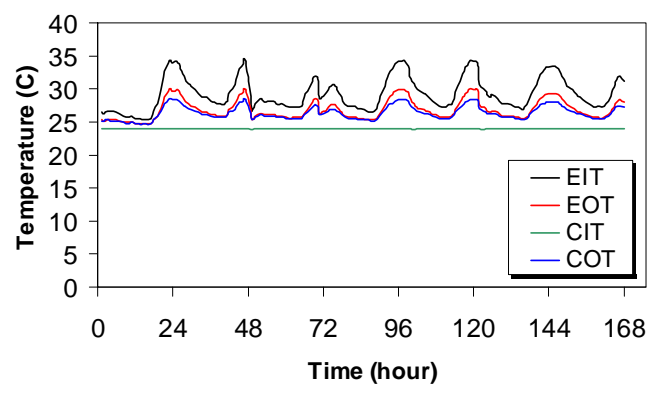

Figure 4. The recorded temperature and $\mathrm{RH}$ of the measuring points

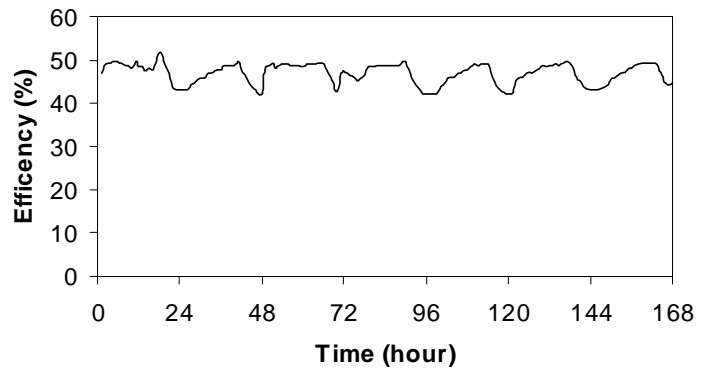

Figure 5. Recorded efficiency during the test

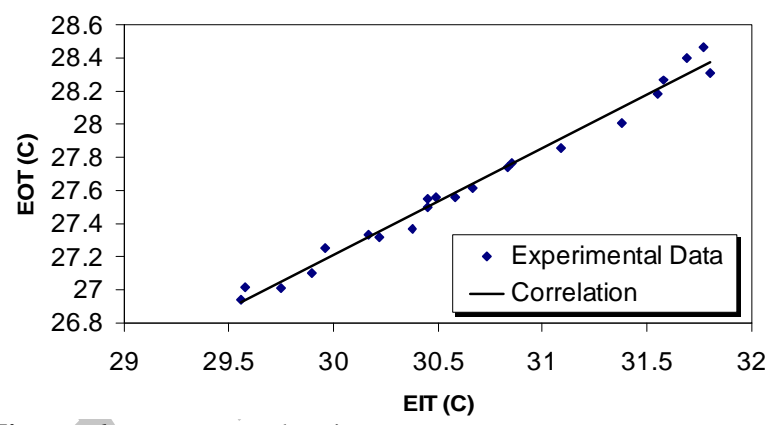

Figure 6. Evaporator leaving temperature versus evaporator inlet temperature for typical $60 \% \leq \mathrm{RH}<70 \%$

TABLE 2. Empirical equations

\begin{tabular}{l|ll}
\hline 1 & $0 \%<R H \leq 50 \%$ & $E O T=0.6628 * E I T+7.195$ \\
2 & $50 \%<R H \leq 60 \%$ & $E O T=0.645 * E I T+7.822$ \\
3 & $60 \%<R H \leq 70 \%$ & $E O T=0.6476 * E I T+7.7807$ \\
4 & $70 \%<R H \leq 80 \%$ & $E O T=0.5866 * E I T+9.6301$ \\
5 & $80 \%<R H \leq 100 \%$ & $E O T=0.5017 * E I T+12.005$ \\
\hline
\end{tabular}

The predicted TMY weather files were generated by adapting the current industry standard weather files to incorporate climate change predictions [13]. The data files provide the hourly weather data for the whole year of 8760 hours for the tropical Kuala Lumpur climate.

The hour-by-hour weather data together with the relevant empirical equations were used for the calculations of the energy recovery by the HPHX. Therefore, the empirical equations of the HPHX, which were extracted from the performance curves, were written as a FORTRAN source code to represent the HPHX in TRNSYS software (TRNSYS software is a transient systems simulation software with a modular structure).

TRNSYS software was used to read the hour-byhour data from the TMY weather files and compute the data for the whole years. Then, the energy recovery by the HPHX evaporator section was simulated hour-byhour for the whole year of $8760 \mathrm{~h}$. This prediction was 
performed for the years of 2000, 2020, and 2050, as illustrated in Figures 7-9.

Based on the simulation results, it was found that the energy recovery by the evaporator section of the HPHX was estimated at $3397 \mathrm{kWh}, 5639 \mathrm{kWh}$, and $7066 \mathrm{kWh}$ for 2000, 2020, and 2050, respectively. Moreover, if the energy rejected in the condenser section could be used for heating process, the amount of energy recovery by the HPHX could be increased up to $6794 \mathrm{kWh}$, $11278 \mathrm{kWh}$, and $14132 \mathrm{kWh}$ for the years 2000, 2020, and 2050, respectively. Table 3 shows the capability of the HPHX for energy recovering. As tabulated in Table 3 , the energy recovery potential of the HPHX increases from 2000 to 2050. In percentage terms, the predictions showed that the energy recovery potential of the fabricated HPHX could increase up to $66 \%$ and $108 \%$ in years 2020 and 2050 in comparison to year 2000, respectively. This is attributed to the fact that, the inlet temperature to the evaporator section would be higher in coming years; therefore, the temperature drop in the evaporator section expected to be increased.

It is clear that the amount of energy recovery by a heat exchanger depends on the amount of the ventilated air in the system. As already explained, the above described climate chamber is a small scale of the AC systems.

In the climate chamber under test, the system received 622 CFM (cubic feet per minute) of air, which was almost suitable for a small room of about $20 \mathrm{~m}^{3}$, and the energy recovered by the HPHX was based on the above ventilated air; therefore, it could be anticipated that the amount of energy recovery in the actual AC systems would be much higher than the above mentioned amounts. For example, in the study reported in [11] the energy saving of the system with the added loop heat pipe was estimated to be about 140 $\mathrm{kW} / \mathrm{h}$, which is considerable in an actual AC system.

Therefore, by considering all the above, HPHXs as an environmentally friendly technology could be an appropriate heat recovery device for coming years. Moreover, based on the interesting energy recovery capability of the HPHXs in AC systems, AC systems are recommended to be equipped with this heat recovery device to improve the system performance in terms of energy consumption.

\subsection{Uncertainty analysis Bias uncertainty} ( $B_{\text {Tdependent }}$ ) because of the non-uniformity in the temperature profile was estimated for the recorded parameters in this research. The bias uncertainty for the dependent variables that results from a non-uniform temperature distribution at a measuring point can be approximately represented by:

$$
B_{\text {Tdependent }}=\frac{X_{\max }-X_{\min }}{n}
$$

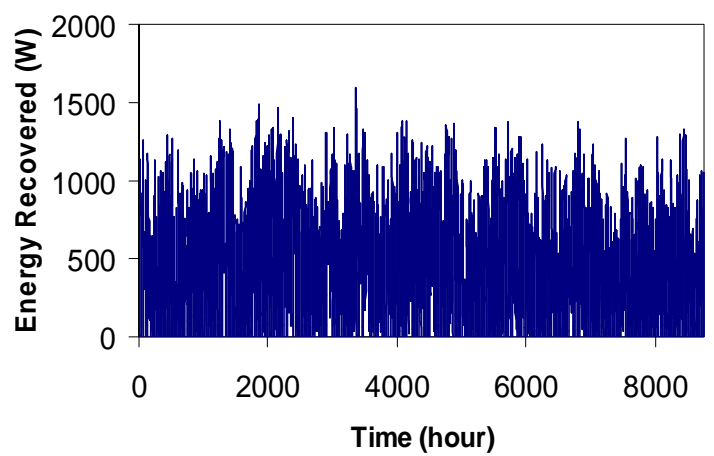

Figure 7. Energy recovered by the evaporator section of the HPHX, simulation for the whole year- year 2000

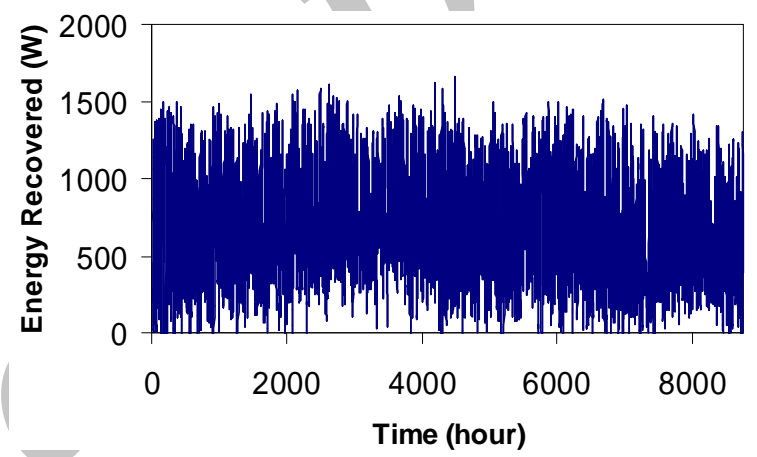

Figure 8. Energy recovered by the evaporator section of the HPHX, simulation for the whole year- year 2020

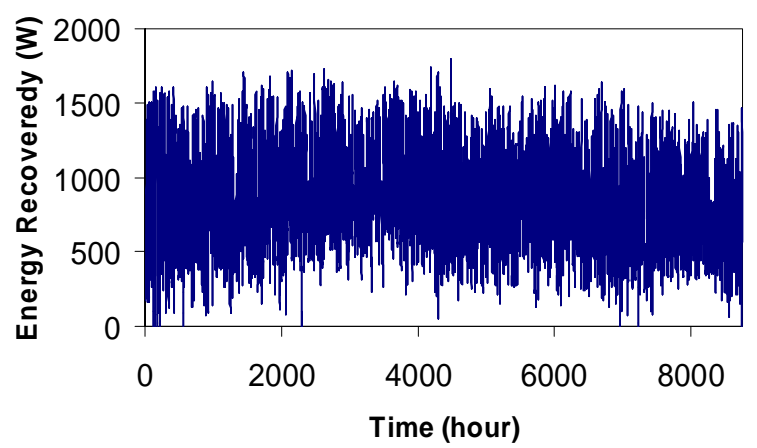

Figure 9. Energy recovered by the evaporator section of the HPHX, simulation for the whole year- year 2050

TABLE 3. Energy recovery by the HPHX

\begin{tabular}{llll}
\hline Year & $\begin{array}{l}\text { By the } \\
\text { evaporator } \\
\text { section of the } \\
\text { HPHX }(\mathbf{k W h})\end{array}$ & $\begin{array}{l}\text { By the } \\
\text { evaporator } \\
\text { and condenser } \\
\text { sections of the } \\
\text { HPHX }(\mathbf{k W h})\end{array}$ & $\begin{array}{l}\text { Improvement } \\
(\boldsymbol{\%})\end{array}$ \\
\hline 2000 & 3397 & 6794 & - \\
2020 & 5639 & 11278 & 66 \\
2050 & 7066 & 14132 & 108 \\
\hline
\end{tabular}


where $X$ is the dependent variable (effectiveness and EBR in this research), $n$ is the number of dependent variables, $X_{\max }$ and $X_{\min }$ are the maximum and minimum dependent variables calculated based on the maximum and minimum temperatures at the measuring points.

In this study, the bias uncertainty for the hourly recorded effectiveness and EBR was calculated. To this end, maximum amount of parameter $\left(X_{\max }\right)$ is calculated based on the maximum recorded temperature at the measuring points and minimum amount of parameter $\left(X_{\text {min }}\right)$ is calculated based on the minimum recorded temperature at the measuring points. Figure 10 shows the hourly calculated bias uncertainty for the effectiveness and EBR parameters. It was found that the uncertainty for the EBR values was ranging from $0 \%$ to $6.8 \%$ and for effectiveness parameter was varied from of $0 \%$ to $4.9 \%$.

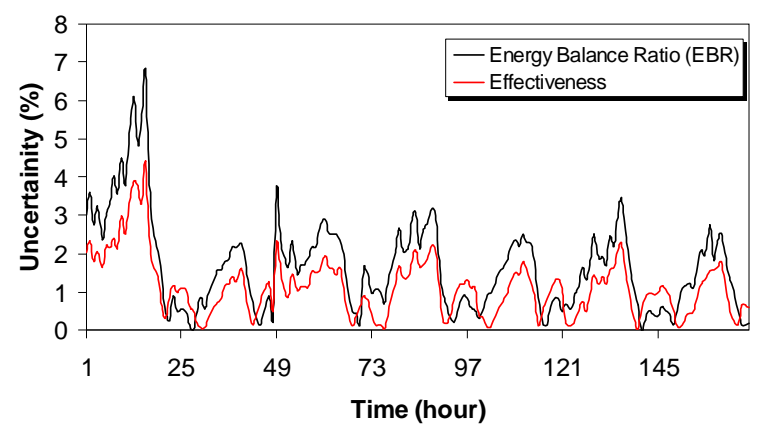

Figure 10. Hourly calculated bias uncertainty for the EBR and effectiveness

\section{CONCLUSION}

In this research, the capability of HPHXs for energy recovering was estimated for the whole year of $8760 \mathrm{~h}$ at 2000, 2020, and 2050. For this purpose, the empirical performance equations of the HPHX were used in TRNSYS software. Based on the simulation results, the fabricated eight-row HPHX has the capability of energy recovery at $6794 \mathrm{kWh}, 11278 \mathrm{kWh}$, and $14132 \mathrm{kWh}$ for the years 2000, 2020, and 2050, respectively. Moreover, the predictions showed that the energy recovery potential of the fabricated HPHX could increase up to $66 \%$ and $108 \%$ in years 2020 and 2050 in comparison to year 2000, respectively. Therefore, it is anticipated that HPHXs can recover a considerable amount of energy in a yearly operation if they could be installed in the actual $\mathrm{AC}$ systems and they are recommended to be used in the $\mathrm{AC}$ systems to improve the systems performance in terms of energy consumption.

\section{ACKNOWLEDGMENTS}

The author would like to acknowledge the financial assistance from the Chabahar Maritime University, Iran and University of Malaya, Malaysia for the research work.

\section{REFERENCES}

1. Hunt, V.D., Handbook of conservation and solar energy, trends and perspectives. Van Nostrand Reinhold Company, (1982).

2. Yau, Y.H., "The use of a double heat pipe heat exchanger system for reducing energy consumption of treating ventilation air in an operating theatre - A full year energy consumption model simulation", Energy and Buildings, Vol. 40, (2008), 917925 .

3. Abd El-Baky, M.A. and Mohamed, M.M., "Heat pipe heat exchanger for heat recovery in air conditioning", Applied Thermal Engineering, Vol. 27, (2007), 795-801.

4. Shirey III, D.B., "Demonstration of efficient humidity control techniques at an art museum", ASHRAE Transactions, Vol. 99, No. 1, (1993), 694-703.

5. Azad, E., "Interconnected heat pipe solar collect", International Journal of Engineering Transactions A: Basics, Vol. 22, No. 3, (2009), 233-242.

6. Abtahi, H., Jayanth, M. and Khattar, M.K., "Theoretical Analysis of the Performance Characteristics of Dehumidification Heat Pipe Heat Exchangers in Air-Conditioning Systems", In ASME Proceedings of the 1988 National Heat Transfer Conference, Houston, TX, USA, Vol. 2, (1998), 1391-1396.

7. Khattar, M.K., "Heat pipes for terrestrial applications in dehumidification systems", Space Congress, $25^{\text {th }}$, Proceedings (A88-52317 23-12), FL, USA, 26-29, (1988).

8. Mathur, G.D., "Predicting yearly energy savings using BIN weather data with heat pipe heat exchangers", In Proceeding of the Intersociety Energy Conversion Engineering Conference, Honolulu, USA, Vol. 2, (1997), 1391-1396.

9. Yau, Y.H., "Application of a heat pipe heat exchanger to dehumidification enhancement in a HVAC system for tropical climates- a base line performance characteristic study", International Journal of Thermal Science, Vol. 46, (2007), 164-171.

10. Yau, Y.H., "Analysis of enthalpy change with/without a heat pipe heat exchanger in a tropical air conditioning system", International Journal of Energy Research, Vol. 30, No. 15, (2006), 1251-1263.

11. Wan, J.W., Zhang, J.L. and Zhang, W.M., "The effect of heat pipe air handling coil on energy consumption in central air conditioning system", Energy and Buildings, Vol. 39, (2007), 1035-1040.

12. Wu, X.P., Johnson, P. and Akbarzadeh, A., "Application of heat pipe heat exchangers to humidity control in air-conditioning systems", Applied Thermal Engineering, Vol. 17, No. 6, (1997), 561-568.

13. Jentsch, M.F., Chang, C.K., James, P.A.B., Bahaj, A.S. and Yau, Y.H., "Development of Climate Change Adapted Weather Files for Building Performance Simulation: Implications for Southeast Asia”, World Renewable Energy Congress 2009 - Asia, The 3rd International Conference on Sustainable Energy and Environment (SEE 2009), Bangkok, Thailand, (2009). 


\section{Energy Conservation Potential of the Heat Pipe Heat Exchangers: Experimental Study and Predictions}

M. Ahmadzadehtalatapeh ${ }^{a}$,Y. H. Yau ${ }^{\mathrm{b}}$

a Department of Marine Engineering, Chabahar Maritime University, 99717-56499, Chabahar, Iran

${ }^{b}$ Department of Mechanical Engineering, University of Malaya, 50603 Kuala Lumpur, Malaysia

\section{$P A P E R \quad I N F O$}

جكيده

Paper history:

Received 7 Aprill 2012

Received in revised form 25 Aprill 2012

Accepted 26 May 2012

\section{Keywords:}

Air Conditioning System

Energy Recovery

Heat Pipe Heat Exchanger

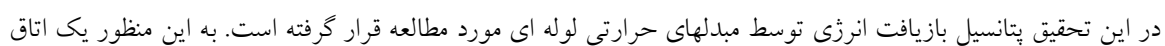

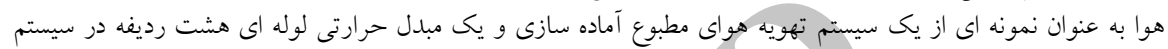

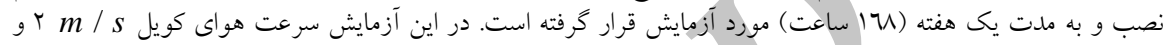

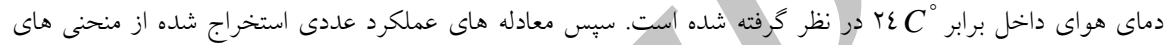

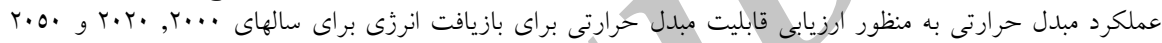

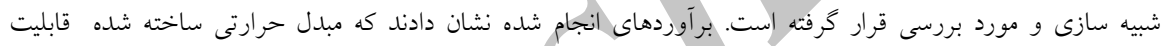

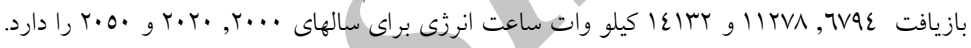

doi: 10.5829/idosi.ije.2012.25.03b.06 


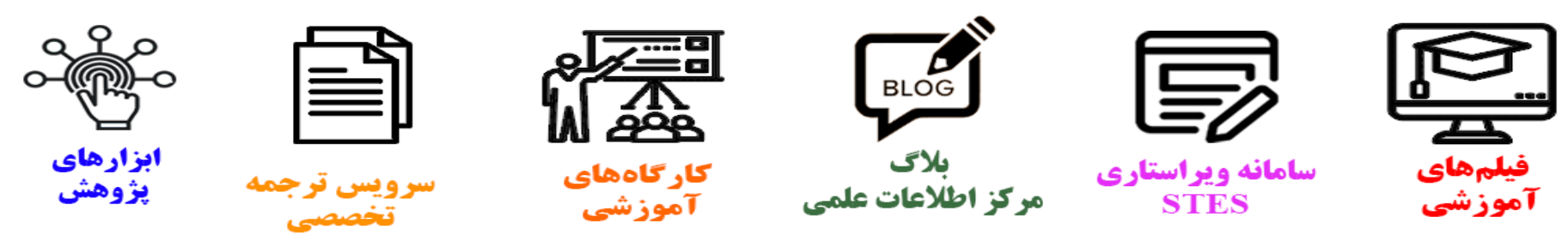

\section{(c)}

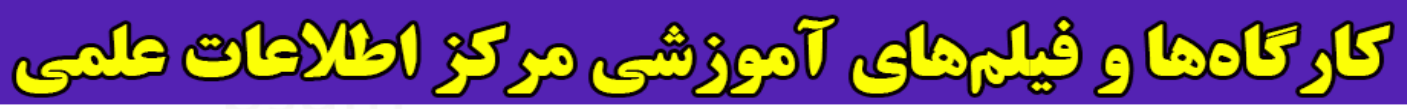
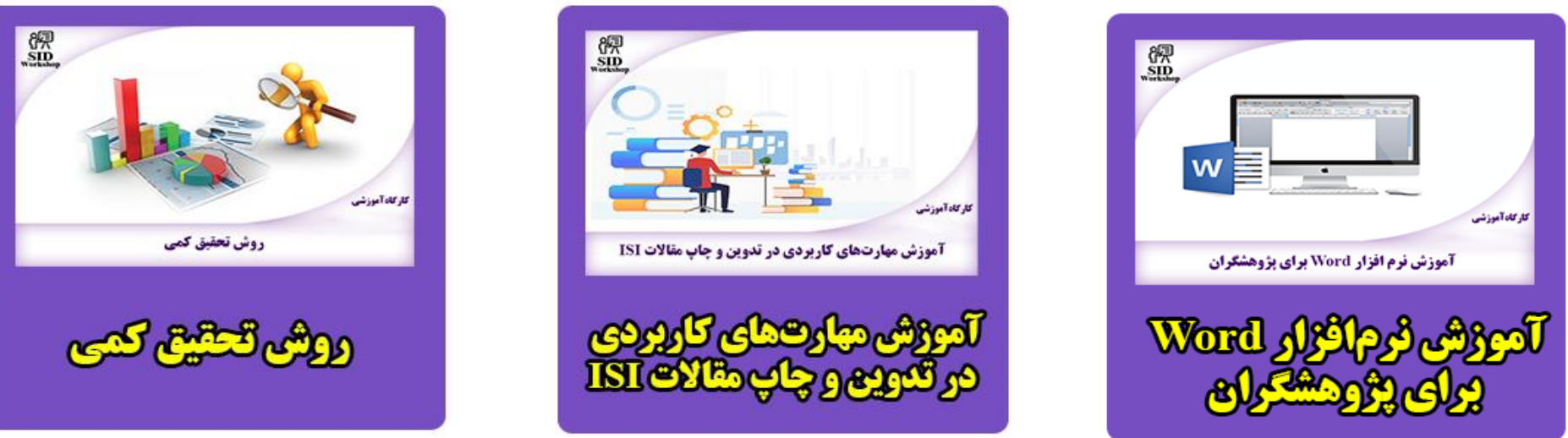